\title{
Justiça Distributiva em Crianças de 5 a 10 Anos de Idade
}

\author{
Distributive Justice in Children from 5 to 10 Years of Age \\ Leonardo Rodrigues Sampaio*a, Cleonice P. dos Santos Camino ${ }^{\text {b }}$ \& Antonio Roazzi ${ }^{\mathrm{c}}$

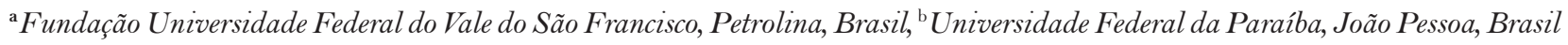 \\ ${ }^{c}$ Universidade Federal de Pernambuco, Recife, Brasil
}

\begin{abstract}
Resumo
O objetivo principal desta pesquisa foi investigar os tipos de princípios de justiça distributiva utilizados por crianças de diferentes faixas etárias. Participaram deste estudo 120 crianças, com idades variando entre 5 e 10 anos, de ambos os sexos. Suas concepções sobre justiça distributiva foram avaliadas através de um dilema constituído por quatro histórias, nas quais duas crianças tinham que decidir dar ou não mais blocos de brinquedo a uma outra criança que chegava atrasada à escola. Os resultados mostraram que (a) uma tendência ao igualitarismo absoluto caracteriza, sobretudo, as crianças de 5 a 6 anos; (b) a utilização de julgamentos eqüitativos torna-se cada vez maior à medida que a idade das crianças avança; (c) os julgamentos que levavam em consideração a importância da cooperação e do respeito mútuo foram identificados mesmo em crianças de 5 a 6 anos. Enfim, estes resultados são discutidos no contexto da pesquisa sobre o desenvolvimento moral infantil e a justiça distributiva.

Palavras-chave: Justiça distributiva; desenvolvimento; igualdade; eqüidade.
\end{abstract}

\begin{abstract}
The main aim of this research was to investigate the types of principles of distributive justice. A sample of 120 children, whose ages ranged from 5 to 10 years, of both sexes, took part in the investigation. Their conceptions about distributive justice were evaluated through a dilemma constituted by four stories, in which two children had to decide whether or not to give more toy blocks to another child that arrived late at school. The results showed that (a) a tendency to absolute equality characterizes children of 5 to 6 years old; (b) the use of equity judgments increase with age; (c) the judgments that considered the importance of cooperation and mutual respect were present even in children 5 to 6 years old. Finally, these results are discussed in the context of research on child moral development and distributive justice.

Keywords: Distributive justice; development; equality; equity.
\end{abstract}

A utilização de princípios de justiça distributiva pode ser estudada a partir de dois tipos de perspectivas: a unidimensional, como a Teoria da Eqüidade de Adams (1965), que propõe que as pessoas distribuem bens e recompensas de acordo com sua percepção sobre as contribuições de cada membro do grupo (princípio da eqüidade), e a abordagem multidimensional, que sugere a existência de diversos princípios de justiça distributiva. Dentro da segunda perspectiva, cita-se o trabalho de Deutsch (1975, 1989) que propõe que o tipo de relação interpessoal e os objetivos dos grupos determinam o tipo de princípio distributivo a ser utilizado: quando se busca alcançar maiores índices de produtividade predomina a equidade; em situações nas quais manter a harmonia grupal é o principal objetivo prevalece o igualitarismo e, por fim, quando uma parte do grupo se responsabiliza pelo desenvolvimento e

\footnotetext{
* Endereço para correspondência: Rua Vinte, 131, apto. 2, Vila Eduardo, Petrolina, PE, 56328-627. Fone: (87) 9106-6011. E-mail: leorsampaio@yahoo.com.br Este artigo é parte da dissertação de Mestrado do primeiro autor, defendida em 2004 no Programa de Pós-Graduação em Psicologia Cognitiva da Universidade Federal de Pernambuco.
}

bem-estar de outras partes, há a tendência de que o princípio da necessidade seja o mais utilizado. Neste trabalho, adotou-se a perspectiva multidimensional, na ótica estrutural-cognitivista de autores como Piaget, Kohlberg e Damon para explicar o desenvolvimento da justiça distributiva.

Para Piaget (1932/1980), a análise sobre o desenvolvimento do conceito de justiça refere-se, principalmente, a duas dimensões distintas: a justiça retributiva, que corresponde à noção de que a justiça deve ser avaliada a partir das relações estabelecidas entre atos e punições; e a justiça distributiva, que corresponde à noção de que o conceito de justiça está diretamente ligado à repartição de bens ou recompensas entre as pessoas.

Com respeito à evolução da justiça retributiva, Piaget (1932/1980) observou que a criança apresenta primeiro uma noção de justiça baseada na punição expiatória e posteriormente uma noção baseada na reciprocidade. Em relação à justiça distributiva ele verificou que, inicialmente, predominava na criança uma noção de distribuição regida por normas impostas de fora; em seguida, prevalecia um igualitarismo absoluto e, por fim, predominavam princípios 
eqüitativos. É importante lembrar que a concepção de Piaget sobre a eqüidade diz respeito a um julgamento que leva em consideração as condições particulares dos sujeitos envolvidos no processo de distribuição e não só os seus níveis de produtividade ou de esforço, como foi sugerido por Adams (1965). Em ambas as dimensões ocorrem evoluções à medida que o sujeito se desvencilha dos efeitos da coação adulta, desenvolve-se cognitivamente, avança nos estágios de tomada de perspectiva do outro - role taking - e passa a agir com base na reciprocidade e na cooperação.

Segundo Lawrence Kohlberg (1976), a justiça é o valor mais importante de uma sociedade e a essência da moralidade. Semelhantemente a Piaget, Kohlberg afirma que quanto mais o sujeito descentra-se, ou seja, avança nos estágios de tomada de perspectiva do outro, mais acurados vão se tornando os seus julgamentos morais (Colby \& Kohlberg, 1987). No que se refere especificamente aos raciocínios sobre justiça distributiva, Kohlberg julga que, na infância, eles se baseiam no respeito absoluto pela autoridade (nível I: pré-convencional); na adolescência, levam em consideração as trocas recíprocas, as convenções e as leis que regem a sociedade (nível II: moral convencional); e a partir do final da adolescência, consideram princípios éticos universais (nível III: moral pós-convencional).

Damon $(1977,1980)$ realizou uma série de pesquisas que investigavam como crianças raciocinavam sobre questões de justiça distributiva e a forma como estas noções evoluíam à proporção que elas se tornavam mais velhas. Nos resultados de suas pesquisas, Damon constatou que as crianças, já a partir dos 3 anos de idade, eram capazes de apresentar argumentos morais e de utilizar princípios distributivos mais complexos do que os que foram sugeridos por Piaget (1932/ 1980) e Kohlberg (1976). Com base em seus resultados, criou sub-níveis de desenvolvimento da justiça que, de uma maneira geral, seguem o princípio piagetiano de que os raciocínios infantis tornam-se cada vez mais complexos, à medida que a criança se desenvolve cognitivamente, em uma caminhada progressiva em direção à eqüidade e que passa pelo igualitarismo absoluto. Damon sugere que, por exemplo, crianças entre 3 e 4 anos de idade utilizam princípios distributivos que se baseiam em seus desejos pessoais, enquanto as crianças após os 10 anos de idade são capazes de coordenar princípios de igualdade e reciprocidade, e os motivos pessoais dos envolvidos na situação de distribuição.

Além dos estudos de Piaget (1932/1980) e Damon (1977, 1980), uma grande variedade de pesquisas tem investigado a relação entre a utilização de princípios de justiça distributiva e outras variáveis. Os resultados dessas pesquisas, de uma maneira geral, indicaram a existência de um avanço na utilização de princípios de justiça distributiva ao longo da infância (Dell'Aglio \& Hutz, 2001; Sales, 2000; Sigelman \& Waitzman, 1991), a influência da manipulação experimental sobre os julgamentos (Hutz, Conti \& Vargas, 1994; McGillienddy-De Lisi, Watkins \& Vinchur, 1991; Sales, 2000), diferenças nos julgamentos decorrentes da origem cultural (Giacobbe-Miller, Miller \& Victorov, 1998; Murphy-Berman \& Berman, 2002) e a influência do sexo dos respondentes na utilização de princípios da justiça distributiva (Leventhal \& Lane, 1970).

No que diz respeito especificamente aos estudos realizados no Brasil, observou-se que existem diferenças significativas nos raciocínios distributivos à medida que a idade avança (Sales, 2000), havendo correspondência entre os princípios utilizados por algumas crianças brasileiras e aqueles investigados por Damon (1977, 1980); que o modelo desenvolvimentista proposto por Piaget (1932/1980) tende a ser corroborado e que observam-se sub-níveis dentro das três grandes etapas propostas por este autor para o desenvolvimento da justiça distributiva (Dell'Aglio \& Hutz, 2001).

Destaca-se o fato de que na maioria das pesquisas citadas anteriormente foram utilizadas situações que envolviam a relação entre a produtividade e o esforço dos personagens para avaliar a justiça distributiva. A prevalência desse tipo de estratégia metodológica permite supor que seriam obtidos resultados diferentes caso fossem utilizadas situações de outros tipos. Julgando importante para o aprofundamento do tema verificar esta suposição, o presente estudo foi concebido. Neste sentido, na presente pesquisa utilizaram-se situações de brincadeira comuns ao dia-a-dia das crianças, nas quais se buscava verificar a influência de variáveis como idade dos personagens e a maneira como eles pediam brinquedos aos outros personagens sobre o julgamento distributivo de crianças em diferentes faixas etárias.

\section{Método}

\section{Participantes}

Foram participantes desse estudo 120 crianças de ambos os sexos, de duas escolas particulares da cidade de Campina Grande - PB, divididas em três faixas etárias: 5 a 6 anos, 7 a 8 anos e 9 a 10 anos de idade. Os participantes de 5 a 6 anos eram estudantes do Jardim II, Alfabetização e $1^{\mathrm{a}}$. série do Ensino Fundamental; os de 7 a 8 e 9 a 10 anos eram estudantes, respectivamente, da $1^{\mathrm{a}}$. e $2^{\mathrm{a}}$., e $3^{\mathrm{a}}$. e $4^{\mathrm{a}}$. séries do Ensino Fundamental.

\section{Instrumento}

Para avaliar as concepções infantis sobre a justiça distributiva, as crianças foram incentivadas a vivenciar dilemas e a resolvê-los, através da descrição de quatro histórias, cujos personagens brincavam em um centro de blocos (playground) de sua escola. Nas histórias, era dito que dois personagens - o cachorrinho verde (CV) e o cachorrinho amarelo (CA) - já estavam lá brincando de construir um zoológico, quando chegava um terceiro personagem - o cachorrinho rosa (CR), o cachorrinho laranja (CL) ou o cachorrinho branco $(\mathrm{CB})$ - que decidia construir um prédio bem alto. Entretanto, ao constatar que o número de blocos restante era insuficiente, o terceiro personagem resolvia pedir mais blocos aos outros dois. De acordo com a situação problema, havia no playground um total de 19 blocos de montar e três animais de brinquedo. Uma vez que para ceder mais blocos ao terceiro personagem os dois primeiros deveriam alterar seu zoológico - o que acarretaria a fuga dos animais 
que lá se encontravam -, ocorria um dilema entre o direito do terceiro personagem de brincar com os blocos e o direito dos outros dois personagens de continuar usando quantos blocos necessitassem em sua brincadeira.

Os dilemas eram apresentados em quatro condições:

1. Na História A, o terceiro personagem (CR) chegava depois que os outros dois já tinham começado a brincar e pedia educadamente mais bloco.

2. Na história B, o terceiro personagem (CL) chegava atrasado e dizia que era mais novo do que os outros dois.

3. Na História C, o terceiro personagem (CB) chegava atrasado e exigia, de forma grosseira e mal-educada, que os outros lhe cedessem mais blocos. Além disto, ele bagunçava o zoológico já montado.

4. Na história D, os três personagens (CV, CA e CR) começavam a brincar ao mesmo tempo. Esta história foi considerada como sendo a de controle, pois a meta era verificar se as crianças adotavam um princípio igualitário de divisão quando os três personagens partiam de uma condição de igualdade (nenhum deles havia se atrasado). Uma parte final do instrumento foi destinada à coleta de informações pessoais dos respondentes como idade, escolaridade e sexo.

\section{Procedimentos}

Antes da realização da coleta de dados, o pesquisador procurou a diretoria das duas escolas para apresentar a proposta de estudo e para solicitar sua colaboração na realização da pesquisa. Tendo obtido autorização para a coleta de dados, foi encaminhado aos pais dos alunos, por meio das professoras, um termo de consentimento livre e esclarecido, que explicava todos os objetivos e procedimentos a serem adotados durante a investigação. Logo após os pais terem autorizado a participação de seus filhos nesta pesquisa, deuse início à coleta de dados.

Em cada história, as crianças decidiam qual deveria ser o comportamento do CA e do CV, segundo as condições relatadas anteriormente. Na história $\mathrm{D}$, as crianças deveriam dizer como poderiam ser divididos todos os blocos e os animais de brinquedo entre os três cachorrinhos. Neste caso, quando a criança adotava um princípio igualitário de divisão - dando seis blocos para cada um - perguntava-se à criança se o bloco restante deveria ser dado a algum dos três personagens. Para cada resposta emitida em cada uma das histórias, solicitavase que as crianças justificassem por que os personagens deveriam proceder da maneira relatada por elas.

Ao final de cada história era dito à criança que as aulas haviam acabado e que antes de ir para casa os cachorrinhos deveriam arrumar todos os brinquedos. Quanto ao início de cada história, a partir da segunda, era dito que no dia seguinte os personagens se encontraram e foram brincar novamente no centro de blocos.

Durante a entrevista, o pesquisador, ao contar a história, ilustrou-a com o uso de bonecos, blocos e animais de brinquedo. Após ouvir a história, a criança emitia sua opinião sobre a distribuição dos blocos, ao mesmo tempo em que mostrava, manipulando os bonecos e os blocos, como a divisão deveria ser feita. Os dados referentes às quantidades de blocos distribuídas, além de algumas observações sobre eventos ocorridos ao longo das entrevistas, foram anotados nos protocolos de cada respondente. Todas as entrevistas foram gravadas em fitas cassetes, que foram transcritas posteriormente. A fim de controlar o efeito da ordem das histórias nas decisões das crianças, foram utilizadas quatro ordens de apresentação.

As respostas objetivas (sim e não), após levantamento das freqüências, foram analisadas através do Qui-quadrado. Além disto, foram utilizados testes não-paramétricos (Kruskal-Wallis, Mann-Whitney, Wilcoxon e Friedman) para comparar as médias e para verificar a influência das variáveis idade e sexo do respondente sobre a quantidade de blocos distribuídos para cada personagem. As justificativas dadas pelas crianças foram submetidas à análise de conteúdo e categorizadas por dois juízes e houve um nível de $95 \%$ de concordância entre as categorizações. Nos casos em que não se chegava ao consenso, um terceiro juiz emitia sua opinião, que servia como critério de desempate. Todas as análises estatísticas foram feitas com o auxílio do software estatístico SPSS for Windows, versão 7.5.

\section{Resultados}

Os resultados foram analisados considerando a quantidade de respostas sim e não a várias perguntas (ex: “Eles devem dar mais blocos ao terceiro personagem?’), as justificativas dadas para a distribuição dos blocos e à influência das variáveis sexo e idade sobre os julgamentos das crianças.

\section{Respostas "Sim" e "Não": Histórias $A, B$ e C}

No que se refere às respostas à questão "Eles devem dar mais blocos ao terceiro personagem?', observou-se que nas histórias A e B não houve diferença significativa entre o número de respostas sim e o de respostas não. Na história $\mathrm{C}$, porém, houve diferença significativa, tendo a maioria dos respondentes optado por não dar mais blocos ao CB. Neste caso, o teste do Qui-quadrado indicou haver diferença significativa $\left(\chi^{2}=19,20 ;\right.$ g.l. $\left.=1 ; \mathrm{p}<0,001\right)$ entre o número de respostas favoráveis e o de respostas contrárias.

Quando o Qui-quadrado foi utilizado para avaliar a diferença entre o número de respostas sim e não emitidas pelos meninos e entre as respostas sim e não emitidas pelas meninas nas três histórias, constatou-se, apenas na História C, a existência de diferenças significativas. Tanto os meninos $\left(\chi^{2}=9,618 ;\right.$ g.l. $\left.=1 ; \mathrm{p}=0,002\right)$ quanto as meninas $\left(\chi^{2}=\right.$ $9,615 ;$ g.l. $=1 ; \mathrm{p}=0,002)$ afirmaram que não se deveria dar mais blocos ao CB.

Quando se analisou a quantidade de respostas sim e não emitidas por cada grupo etário, para cada história, constataramse diferenças significativas. Os resultados do Qui-quadrado indicaram que tanto as crianças de 7 a $8 \operatorname{anos}\left(\chi^{2}=12,1\right.$; g.l. $=1 ; \mathrm{p}=$ 0,001), como as de 9 a 10 anos $\left(\chi^{2}=10,0 ;\right.$ g.l. $\left.=1 ; p=0,002\right)$, responderam, sobretudo, não à pergunta sobre dar mais blocos ao personagem atrasado (Tabela 1) a seguir. 
Tabela 1

Freqüências de Respostas "Sim" e "Não" Emitidas por cada Faixa Etária nas Três Histórias

\begin{tabular}{cccccccc}
\hline $\begin{array}{c}\text { Eles devem dar } \\
\text { mais blocos? }\end{array}$ & & \multicolumn{2}{c}{5 a 6 anos } & \multicolumn{2}{c}{7 a 8 anos } & \multicolumn{2}{c}{9 a 10 anos } \\
\cline { 2 - 7 } & $\%$ & freq. & $\%$ & freq. & $\%$ & freq. \\
\hline História A & sim & 32,4 & 22 & 29,4 & 20 & 38,2 & 26 \\
(educado) & não & 34,6 & 18 & 38,5 & 20 & 26,9 & 14 \\
História B & sim & 34,3 & 24 & 25,7 & 18 & 40 & 28 \\
(mais novo) & não & 32,0 & 16 & 44,0 & 22 & 24,0 & 12 \\
História C & sim & 47,2 & 17 & 25,0 & 9 & 27,8 & 10 \\
(mal-educado) & não & 27,4 & 23 & 36,9 & 31 & 35,7 & 30 \\
\hline
\end{tabular}

\section{Respostas "Sim” e "Não": História D}

A análise das respostas à questão "Você acha que alguém deve ficar com mais? Ou todos eles deveriam ficar com o mesmo número de blocos?' mostrou que a maior parte das crianças ( $95 \%$ da amostra) afirmou que se deveria fazer uma divisão igualitária entre os blocos, quando os três cachorros chegavam à escola ao mesmo tempo $\left(\div^{2}=97,20\right.$; g.l. $=1$ e p $\left.<0,001\right)$. Apenas seis crianças ( $5 \%$ da amostra) - sendo estas pertencentes à faixa etária de 5 a 6 anos - afirmaram que a divisão não deveria ser igualitária na história D. Note-se que a solução de uma divisão igualitária não sofreu influência das variáveis sexo e faixa etária. Por fim, observou-se que todas as crianças que afirmaram ser necessária a utilização de uma distribuição igualitária concordaram que o bloco que sobrava não deveria ser dado a nenhum dos personagens.

\section{Quantidades de Blocos Distribuídas}

No que se refere às quantidades de blocos distribuídas aos personagens das três histórias, foi constatado que o maior número de blocos foi dado ao terceiro personagem quando este era mais novo $(M=7,83 ; D P=4,95)$ que os outros dois que já estavam brincando. Por outro lado, observou-se que quando o personagem atrasado pediu os blocos com raiva $(\mathrm{CB})$, os respondentes lhes deram a menor quantidade de blocos $(M=6,04 ; D P=4,2)$. O personagem bemeducado, por sua vez, recebeu em média 7,72 blocos $(D P=$ $4,93)$. O teste de Wilcoxon indicou que havia diferenças significativas quando se comparava a quantidade de blocos dada ao cachorro bem-educado com a quantidade de blocos dada ao cachorro mal-educado $(z=4,12 ; p<0,001)$, e quando se comparava a quantidade de blocos dada ao cachorro mais novo com a quantidade de blocos dada ao cachorro mal-educado $(z=4,80 ; p<0,001)$.

Para verificar os efeitos das variáveis sexo, idade e ordem de aplicação nas quantidades de blocos distribuídas, utilizou-se o teste de Kruskal-Wallis. Nenhum efeito principal foi observado quando se considerou a relação entre as quantidades de blocos distribuídas e o sexo dos respondentes e entre a quantidade de blocos e a ordem de aplicação das histórias. Porém, observou-se um efeito significativo da idade sobre a quantidade de blocos distribuída na História $\mathrm{C}\left(\chi^{2}=6,266\right.$; g.l. $=2$ e $\left.p=0,04\right)$. Para verificar os grupos de idade que se diferenciavam, foi utilizado o teste de Mann-Whitney. O resultado deste teste indicou que a quantidade média de blocos distribuída pelas crianças do grupo de 5 a 6 anos era significativamente superior $(\mathrm{U}=618,00 ; p=0,035)$ à quantidade média distribuída pelas crianças de 7 a 8 anos, e significativamente superior $(\mathrm{U}=618,00 ; p=0,037)$ à quantidade média distribuída pelas crianças de 9 a 10 anos de idade (ver Tabela 2).

Além disto, o teste de Friedman foi utilizado para verificar se as quantidades médias de blocos dadas por cada faixa etária diferiam ao longo das três histórias. Os resultados indicam que as quantidades de blocos distribuídas pelas crianças de 5 a 6 nas histórias $\mathrm{A}, \mathrm{B}$ e $\mathrm{C}$ não foram significativamente diferentes. Já as crianças de 7 a 8 e de 9 a 10 anos de idade deram quantidades diferentes de blocos para os três personagens. Os resultados do teste para a segunda e a terceira faixa etária são, respectivamente: $\chi^{2}=13,71$; g.l. $=2$ e $p=0,001$ e $\chi^{2}=20,37$; g.l. $=2$ e $p<0,001$.

Tabela 2

Quantidades Médias de Blocos Distribuídas para o Personagem Atrasado por Faixa Etária em cada uma das Três Histórias

\begin{tabular}{ccccccc}
\hline \multirow{2}{*}{ História } & $\begin{array}{c}5 \text { a } 6 \text { anos } \\
(\mathrm{n}=40)\end{array}$ & \multicolumn{2}{c}{$\begin{array}{c}7 \text { a } 8 \text { anos } \\
(\mathrm{n}=40)\end{array}$} & \multicolumn{2}{c}{$\begin{array}{c}9 \text { a } 10 \text { anos } \\
(\mathrm{n}=40)\end{array}$} \\
\cline { 2 - 7 } & $\mathrm{m}$ & $\mathrm{DP}$ & $\mathrm{m}$ & $\mathrm{DP}$ & $\mathrm{m}$ & $\mathrm{DP}$ \\
\hline $\mathrm{A}$ & 8,40 & 5,75 & 7,18 & 4,80 & 7,58 & 4,15 \\
B & 9,02 & 5,98 & 6,55 & 4,08 & 7,90 & 4,38 \\
$\mathrm{C}$ & 7,65 & 5,54 & 5,37 & 3,49 & 5,10 & 2,69 \\
\hline
\end{tabular}

\section{Justificativas}

Nos casos em que as respostas explicavam por que o CA e o $\mathrm{CV}$ deveriam dar mais blocos ao personagem atrasado (CR, $\mathrm{CB}$ ou $\mathrm{CL}$ ), as categorias criadas foram as seguintes: Evitar conseqüências negativas: $\mathrm{CA}$ e $\mathrm{CV}$ deveriam buscar a preservação do bem-estar (psicológico ou físico) dos personagens e evitar que punições lhes fossem aplicadas. Ex: "Para ele não ficar com raiva!"; "Para não haver brigas"; Merecimento: $\mathrm{CA}$ e $\mathrm{CV}$ deveriam considerar o bom comportamento do CR e do CL nas histórias A e B. Ex: "OCL pediu os blocos direitinho"; "Porque ele (CR) chegou bonzinho"; Cooperação/ reciprocidade: o CA e o CV tinham obrigação ou desejo de ajudar o terceiro personagem, pois eles deveriam ser amigos do outro. Ex: "Se eles ficarem com mais blocos serão egoístas"; "Para ele ser amigo dos outros dois"; Satisfazer desejo do ou- 
tro: o CA e o CV deveriam dividir os blocos apenas para satisfazer o desejo do personagem atrasado. Ex: "Só quatro blocos não dá para fazer o prédio delè; "Ele queria brincar também”; Justiça igualitária: os três personagens deveriam ter o mesmo número de blocos ou porque todos têm direitos iguais, desde que estejam em condições semelhantes. Ex: "Os outros dois já brincaram, agora é a vez dele”; "Ninguém pode ficar com mais blocos que o outro"; "Ele é do mesmo tamanho e idade que os outros dois"; Justiça eqüitativa: o CL tinha direito de receber mais blocos porque é mais novo que os outros dois. Algumas justificativas baseavam-se ainda em uma forma de merecimento na qual o comportamento do CL ou suas características físicas eram ressaltados. Ex: "Os maiores têm que dividir com os menores"; "O CL é o mais novo".

As respostas que justificavam a adoção de uma divisão igualitária na História D foram organizadas nas seguintes categorias: Evitar conseqüências negativas: o CA e o CV deveriam buscar a preservação do bem-estar (psicológico ou físico) dos personagens. Exemplos: "Para ninguém ficar com raiva!"; "Para ninguém ficar chorando"; "Para não haver brigas”; Cooperação/reciprocidade: a justificativa baseava-se na manutenção de laços de amizade ou fraternidade entre os personagens. Exemplos: "Para os três não serem egoístas"; "Os três gostam de dividir"; "Os cachorrinhos são amiguinhos"; Justiça igualitária: todos os personagens tinham o mesmo direito de brincar com os blocos. Outras justificativas referiam-se à condição de igualdade dos três personagens e à preservação de um tipo de justiça igualitária. Exemplos: "Para que todos possam brincar"; "Nenhum é melhor que o outro"; "Para não ocorrer uma injustiça”.
Nas três histórias, nos casos em que a criança não justificou sua resposta, ou quando emitiu uma resposta que não condizia com a pergunta que lhe havia sido feita, sua resposta foi categorizada como sendo sem justificativa.

\section{Freqüências das Justificavas}

De uma forma geral, a análise das freqüências das respostas favoráveis a dar mais blocos ao personagem atrasado mostrou que houve um decréscimo de respostas dos tipos Evitar conseqüências negativas e Satisfazer desejo do outro, nas três histórias, à medida que aumentava a faixa etária dos respondentes (Tabelas 3, 4 e 5). Observou-se ainda que o aumento do número de respostas do tipo Cooperação/ Reciprocidade estava relacionado ao aumento da idade dos respondentes. Por fim, respostas do tipo Sem justificativa só foram emitidas por crianças da faixa etária de 5 a 6 anos de idade, nas três histórias.

Analisando-se cada história separadamente, percebeuse que na história A houve uma ampliação do número de respostas do tipo Merecimento e Justiça igualitária à medida que aumentava a idade das crianças. Esta última categoria de resposta só foi observada em respondentes de 7 a 10 anos de idade (Tabela 3).

No que diz respeito à história $\mathrm{B}$, destaca-se que houve uma relação entre o aumento da idade e o aumento da freqüência de respostas do tipo Justiça eqüitativa e Merecimento. Observa-se ainda que as justificativas da categoria Cooperação/ Reciprocidade foram utilizadas, mais intensamente, por respondentes de 7 a 10 anos de idade (Tabela 4).

Tabela 3

Justificativas para dar Mais Blocos ao Personagem Atrasado na História A

\begin{tabular}{lcccccc}
\hline \multirow{2}{*}{ Categorias } & \multicolumn{5}{c}{ Faixa etária } \\
\cline { 2 - 7 } & \multicolumn{2}{c}{ de 5 a 6 anos } & de 7 a 8 anos & \multicolumn{2}{c}{ de 9 a 10 anos } \\
\cline { 2 - 7 } & $\%$ & freq. & $\%$ & freq. & $\%$ & freq. \\
\hline Justiça igualitária & 0 & 0 & 5,0 & 1 & 7,7 & 2 \\
Evitar conseqüências negativa & 31,8 & 7 & 10,0 & 2 & 11,5 & 3 \\
Cooperação/ reciprocidade & 9,1 & 2 & 20,0 & 4 & 30,8 & 8 \\
Satisfazer desejo do outro & 27,3 & 6 & 20,0 & 4 & 0 & 0 \\
Merecimento & 13,6 & 3 & 45,0 & 9 & 50,0 & 13 \\
Sem justificativa & 18,2 & 4 & 0,0 & 0 & 0,0 & 0 \\
Total & 100 & 22 & 100 & 20 & 100 & 26 \\
\hline
\end{tabular}

Tabela 4

Justificativas para dar Mais Blocos ao Personagem Atrasado na História B

\begin{tabular}{|c|c|c|c|c|c|c|}
\hline \multirow[t]{3}{*}{ Categorias } & \multicolumn{6}{|c|}{ Faixa etária } \\
\hline & \multicolumn{2}{|c|}{ de 5 a 6 anos } & \multicolumn{2}{|c|}{ de 7 a 8 anos } & \multicolumn{2}{|c|}{ de 9 a 10 anos } \\
\hline & $\%$ & freq. & $\%$ & freq. & $\%$ & freq. \\
\hline Justiça igualitária & 4,16 & 1 & $\mathrm{O}$ & $\mathrm{O}$ & 3,6 & 1 \\
\hline Evitar conseqüências negativas & 25,0 & 6 & 11,1 & 2 & 3,6 & 1 \\
\hline Cooperação/ reciprocidade & 4,2 & 1 & 22,2 & 4 & 14,3 & 4 \\
\hline Satisfazer desejo do outro & 29,2 & 7 & 11,1 & 2 & 10,7 & 3 \\
\hline Justiça eqüitativa & 20,8 & 5 & 50,0 & 9 & 57,1 & 16 \\
\hline Merecimento & 4,2 & 1 & 5,6 & 1 & 10,7 & 3 \\
\hline Sem justificativa & 12,5 & 3 & $\mathrm{O}, \mathrm{O}$ & $\mathrm{O}$ & 0,0 & $\mathrm{O}$ \\
\hline Total & 100 & 24 & 100 & 18 & 100 & 28 \\
\hline
\end{tabular}


A análise das freqüências das respostas na história $\mathrm{C}$ mostra que as crianças de 5 a 6 anos de idade não utilizaram justificativas categorizadas como Justiça igualitária e que utilizaram pouco as respostas categorizadas como Cooperação/ reciprocidade. Outro fato a ser destacado é que as justificativas incluídas nesta categoria aumentaram à medida que a idade avançava. Por outro lado, na categoria Evitar conseqüências negativas ocorreu diminuição de freqüência à medida que a idade aumentava (Tabela 5).

Analisando-se qual tipo de resposta foi mais utilizado por cada faixa etária para justificar porque o CA e o $\mathrm{CV}$ deveriam dar mais blocos ao cachorro que chegava atrasado, observou-se que as crianças de 5 e 6 anos utilizaram mais justificativas do tipo Evitar conseqüências negativas e Satisfazer desejo do outro, nas histórias A, B e C. Por outro lado, as crianças da segunda e da terceira faixa etária optaram por justificar suas distribuições, sobretudo, com respostas do tipo Merecimento, Justiça eqüitativa e Cooperação/ reciprocidade.

Os resultados mostraram que, para a maioria dos respondentes $(60,83 \%)$, o fator mais importante que justificava a adoção de uma divisão igualitária na História D era a preservação do bem-estar de todos os personagens, havendo, portanto, uma predileção por respostas do tipo Evitar conseqüências negativas. Ao se analisar o número de justificativas apresentadas pelas crianças, levando-se em consideração cada faixa etária, observa-se que houve um aumento da freqüência de respostas dos tipos Justiça Igualitária e Evitar Conseqüências negativas, e a diminuição da freqüência de respostas dos tipos Sem Justificativa e Cooperação/reciprocidade à medida que a idade das crianças avançava (ver Figura 1).

\section{Discussão e Considerações Finais}

De uma maneira geral, observou-se que crianças de diferentes idades utilizaram motivos diferentes para justificar suas divisões. Neste sentido, percebe-se, assim como Damon (1980) afirma, que os raciocínios infantis sobre justiça distributiva podem ser mais diversificados do que foi sugerido por Colby e Kohlberg (1987) e Kohlberg (1976). Além disso, observou-se que questões sobre mérito surgiram bem antes do que foi proposto no modelo teórico kohlbergiano (nível II: convencional).

Apesar de haver predominância de alguns tipos de justificativas em determinadas faixas etárias e de terem sido identificadas tendências de evolução nos raciocínios sobre justiça distributiva, verificou-se que as crianças mais novas foram capazes de construir argumentos com base na importância da cooperação e da reciprocidade, os quais seriam esperados apenas para as crianças mais velhas. Portanto, não se constatou a existência de estágios de desenvolvimento moral altamente delimitados.

A análise dos resultados, no que se refere ao número de respostas sim e não à questão "Eles devem dar mais blocos ao personagem atrasado?', mostra que o mau-comportamento do $\mathrm{CB}$ na história $\mathrm{C}$ foi um fator relevante para as crianças tomarem suas decisões. Esse resultado indica que, de uma maneira geral, as crianças foram capazes de incorporar informações contextuais aos seus julgamentos morais sobre justiça distributiva.

Contudo, ao se analisar a freqüência de respostas sim e não, levando-se em consideração o sexo e a idade dos respondentes, não se observaram diferenças estatisticamente significativas. No que tange às diferenças entre meninos e

Tabela 5

Justificativas para dar Mais Blocos ao Personagem Atrasado na História C

\begin{tabular}{lcccccc}
\hline \multirow{2}{*}{ Categorias } & \multicolumn{5}{c}{ Faixa etária } \\
\cline { 2 - 7 } & \multicolumn{2}{c}{ de 5 a 6 anos } & de 7 a 8 anos & \multicolumn{2}{c}{ de 9 a 10 anos } \\
\cline { 2 - 7 } & $\%$ & freq. & $\%$ & freq. & $\%$ & freq. \\
\hline Justiça igualitária & 0 & 0 & 11,10 & 1 & 10,0 & 1 \\
Evitar conseqüências negativas & 41,1 & 7 & 33,3 & 3 & 30,0 & 3 \\
Cooperação/ reciprocidade & 5,9 & 1 & 44,4 & 4 & 60,0 & 6 \\
Satisfazer desejo do outro & 41,2 & 7 & 11,1 & 1 & 0 & 0 \\
Sem justificativa & 11,8 & 2 & 0,0 & 0 & 0,0 & 0 \\
Total & 100 & 17 & 100 & 9 & 100 & 10 \\
\hline
\end{tabular}

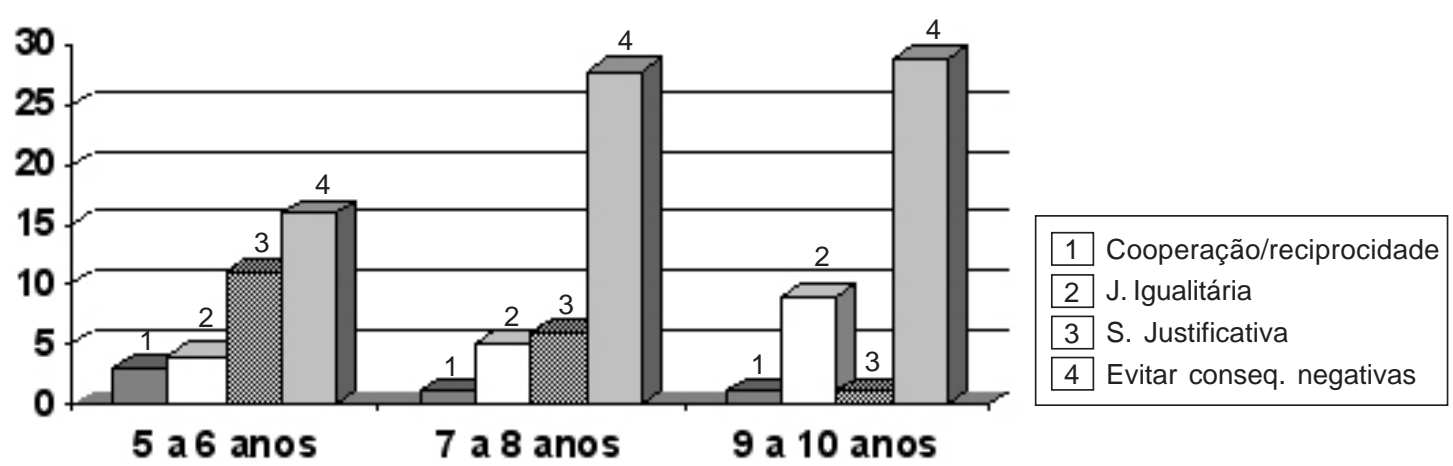

Figura 1. Freqüências das justificativas para realizar uma divisão igualitária na História D. 
meninas, segundo Damon (1980), tal resultado seria esperado nos julgamentos infantis sobre justiça distributiva, uma vez que diferenças de gênero não tenderiam a aparecer nessas faixas etárias.

A análise de cada grupo etário mostra que a quantidade de respostas favoráveis ou contrárias a dar mais blocos ao personagem atrasado, para as crianças de 5 a 6 anos, não sofre variação significativa, entre as histórias A, B e C. Já para os respondentes de 7 a 8 , e de 9 a 10 anos, existem diferenças significativas entre o número de respostas sim e não. Estes resultados sugerem que as crianças mais novas, ao contrário das crianças mais velhas, não foram influenciadas pelas informações que diziam respeito ao comportamento e à idade dos personagens.

Ao se analisar a diferença entre as quantidades de blocos distribuídas, comparando-se as faixas etárias dos respondentes, observa-se que na história $\mathrm{C}$ as crianças mais novas deram mais blocos ao personagem mal-educado (CR) e que o inverso foi verdadeiro para as crianças de 9 a 10 anos de idade. $\mathrm{O}$ resultado apresentado pelas crianças mais velhas pode ser explicado a partir das considerações de Damon (1980). De acordo este autor, os julgamentos que levam em consideração questões sobre merecimento devem surgir por volta dos 10 anos porque nessa idade as crianças tendem a levar em conta os motivos e as intenções dos envolvidos na situação de distribuição.

O fato de as crianças mais novas terem distribuído quantidades médias de blocos semelhantes nas três histórias, parece caracterizar o igualitarismo absoluto predominante nesta idade e indica que, para esta faixa etária, o mau comportamento do $\mathrm{CB}$ não seria motivo suficiente para dar-lhe um tratamento muito diferente do que aquele que foi dado aos outros personagens. Já a forma diferenciada de distribuir os blocos adotada pelas crianças de 9 a 10 anos, inclusive o fato de elas terem favorecido ao CL, parece indicar que essas crianças guiaram-se pelo princípio da eqüidade. Estes resultados estão de acordo com o que Piaget (1932/ 1980) afirma sobre o desenvolvimento da justiça distributiva, especificamente sobre a evolução do igualitarismo até a eqüidade, e seguem a mesma direção apontada pelos resultados dos estudos de McGillienddyDe Lisi et al. (1991), e de Dell'Aglio e Hutz (2001).

De uma forma geral, identifica-se que alguns tipos de justificativas foram mais freqüentemente utilizados por determinadas faixas etárias. Por exemplo, houve uma predominância de respostas dos tipos Evitar conseqüências negativas e Satisfazer desejo do outro entre crianças de 5 a 6 anos de idade. O primeiro tipo de resposta mostra o temor das crianças de que algo de ruim aconteça (brigas, discussões, ou alguém chorar), o que as levaria a considerar este fator como sendo mais importante para a distribuição dos brinquedos. Estes resultados são compatíveis com os achados de Damon (1980), segundo os quais crianças por volta dos 5 anos distribuem bens como forma de evitar punições e situações de conflito, e com a explicação de Piaget (1932/1980) de que nesta faixa etária as crianças possuem uma moral baseada, sobretudo, no respeito unilateral e no medo.
Já a predominância da categoria Satisfazer desejo do outro pode ser vista como um reflexo da limitação das crianças de 5 a 6 anos em analisar informações contextuais e em coordenar as diferentes perspectivas envolvidas na situação de distribuição. Neste sentido, ressalta-se que a maior parte destas crianças focalizou, sobretudo, a vontade de brincar do CR, sem considerar os interesses do CA e do CV. Tendo em vista que, segundo Piaget (1964/1989), tal limitação seria decorrente do egocentrismo infantil presente nesta faixa etária, considera-se que estes resultados fazem sentido, à luz da teoria piagetiana. Destaca-se ainda, que, assim como ocorreu no estudo de Sigelman e Waitzman (1991), respostas sem justificativa só foram observadas entre as crianças mais novas.

Observou-se nos resultados que a justificativa mais evocada pelas crianças de 5 a 6 anos para não dar blocos ao cachorro atrasado, foi a de que se o $\mathrm{CV}$ e o CA dessem mais blocos, o zoológico seria destruído ou alterado. Este tipo de resposta sugere que essas crianças não foram capazes de coordenar plenamente a perspectiva dos personagens que já estavam brincando com a do que chegava depois, e assim adotaram e defenderam apenas o ponto de vista de uma das partes, o que parece confirmar a suposição levantada por Piaget (1964/1989) sobre o egocentrismo infantil.

Uma análise sobre os tipos de justificativas predominantes entre as crianças reflete, mais uma vez, a influência que as informações contextuais e a idade exerceram sobre seus julgamentos: na história A predominaram as justificativas categorizadas como Merecimento; na história B, as categorizadas como Justiça Eqüitativa; e, na história C, as categorizadas como Cooperação/Reciprocidade. Especificamente na análise da história B, observa-se que as crianças de 9 a 10 anos foram as que mais deram justificativas categorizadas como Justiça Eqüitativa. Assim, no que diz respeito à utilização de um princípio mais eqüitativo, o modelo de desenvolvimento proposto por Piaget (1932/ 1980) foi confirmado.

A análise das freqüências das justificativas utilizadas na defesa de uma divisão igualitária indica que manter a harmonia grupal e evitar conseqüências desagradáveis foi um fator primordial para que todos os personagens recebessem as mesmas quantidades de blocos, quando partindo de uma situação de igualdade, e que as crianças mais velhas foram as que mais apresentaram esse tipo de justificativa. Este resultado pode ser ilustrativo da evolução do pensamento moral infantil - da heteronomia para a autonomia -, no sentido de que as crianças mais velhas, por utilizarem um pensamento moral autônomo, estariam mais preocupadas com a manutenção de relações cooperativas e de respeito mútuo entre os personagens das histórias, enquanto que as crianças mais novas estariam preocupadas, sobretudo, com a evitação de conflitos e de situações de incômodo para um dos personagens.

Apesar de não haver confirmação estatística para todas as análises realizadas sobre as diferenças entre os grupos de idade, considera-se que os raciocínios infantis sobre a distribuição tenderam a se tornar mais complexos à medida 
que a faixa etária aumentava, e que este aumento de complexidade foi na direção prevista por Piaget (1932/1980), isto é, de uma moral heterônoma para um pensamento moral autônomo.

Uma vez que o método de investigação utilizado por outros autores (Dell'Aglio \& Hutz, 2001; Hutz et al., 1994; Sales, 2000) é derivado de estudos em que a situação experimental envolvia uma relação direta entre nível de produtividade / esforço $x$ distribuição de recompensas, julga-se que o instrumento usado nesta pesquisa permitiu às crianças expor uma diversidade de justificativas. As diferenças entre os resultados obtidos pelo presente estudo e por outros realizados no Brasil e no mundo contribuem para a ampliação e aprofundamento teórico no campo do desenvolvimento moral infantil uma vez que, como demonstrado, havendo variação no tipo de situação utilizada, há a tendência de que diferentes tipos de raciocínios morais sejam identificados.

Um outro tipo de variação na manipulação experimental que poderia ser incluído em estudos futuros seria a introdução de uma tarefa que avaliasse melhor o domínio da heteronomia. Tal tarefa poderia seguir os moldes indicados pelos estudos de Damon (1977, 1980) e Dell'Aglio e Hutz (2001), entre outros, nos quais se fazem diversos tipos de divisões e solicita-se que a criança julgue se as mesmas são justas ou não, justificando seu pensamento. Sobre este aspecto, considera-se uma limitação do presente estudo uma vez que, questões ligadas ao pensamento heterônomo só puderam ser avaliadas indiretamente quando as crianças se referiram à categoria Evitar conseqüências negativas.

Além disto considera-se que o fato das idades das crianças serem muito próximas contribuiu para que não se identificassem estágios de desenvolvimento altamente delimitados, assim como ocorreu em outros estudos. Neste sentido, sugere-se que em pesquisas futuras seja utilizado um intervalo de dois anos entre as faixas etárias dos respondentes, para que se verifique se a evolução nos julgamentos infantis sobre justiça distributiva pode realmente ser mais bem observada ao longo de dois anos, assim como foi sugerido por Damon (1980).

\section{Referências}

Adams, J. S. (1965). Inequity in social exchange. In L. Berkowitz (Ed.), Advances in Experimental Social Psychology (Vol. 2, pp. 267-299). New York: Academic Press.

Colby, A., \& Kohlberg, L (1987). The measurement of moral judgment: Vol. 1. New York: Cambridge University Press.

Damon, W. (1977). The social Word of the child. San Francisco, CA: Jossey-Bass.
Damon, W. (1980). Patterns of change in children's social reasoning: A two-year longitudinal study. Child Development, 51, 1010-1017.

Dell'Aglio, D. D., \& Hutz, C. S. (2001). Padrões evolutivos na utilização dos princípios de justiça distributiva em crianças e adolescentes no sul do Brasil. Psicologia: Reflexão e Crítica, 14(1), 97-106.

Deutsch, M. (1975). Equity, equality and need: What determines which value will be used as the base of distributive justice? Journal of Social Issues, 31, 137-149.

Deutsch, M. (1989). Equality and economic efficiency: Is there a trade-off? In N. Eisenberg, J. Roykowsky \& E. Staub (Eds.), Social and moral values: Individual and societal perspectives (pp.139-152). Hillsdale, NJ: Erlbaum.

Giacobbe-Miller, J., K., Miller, D. J., \& Victorov, V., I. (1998). A comparison of Russian and U.S. pay allocation decision, distributive justice judgments and productivity under different payment conditions. Personnel Psychology, 1(27), 137-154.

Hutz, C. S., Conti, L., \& Vargas, S. (1994). Rules used by Brazilian students in systematic and nonsystematic reward allocation. Journal of Social Psychology, 134(3), 331-338.

Kohlberg, L. (1976). Moral stages and moralization: The cognitive-developmental approach. In T. Lickona (Ed.), Moral development and behavior: Theory, research and social issues (pp. 31-53). New York: Holt, Rinehart and Winston.

Leventhal, G. S., \& Lane, D. W. (1970). Sex, age, and equity behavior. Journal of Personality and Social Psychology, 15(4), 312-316.

Mcgillienddy-De Lisi, A. V., Watkins, C., \& Vinchur, A. J. (1991). The effect of relationship on children's distributive justice reasoning. Child Development, 65, 1694-1700.

Murphy-Berman, V., \& Berman, J. (2002). Cross-cultural differences in perceptions of distributive justice: A comparison of Hong Kong and Indonesia. Journal of Cross-Cultural Psychology, 33(2), 157-170.

Piaget, J. (1980). O juízo moral na criança (E. Lenardon, Trad.) São Paulo, SP: Mestre Jou. (Original publicado em 1932)

Piaget, J. (1989). Seis estudos de Psicologia. (M. A. M. D’Amorim \& P. S. L. Silva, Trad.). Rio de Janeiro, RJ: Forense Universitária. (Original publicado em 1964)

Sales, E. M. B. (2000). O conceito de justiça distributiva relacionado às normas sociais escolares. Psicologia: Reflexão $e$ Crítica, 13(1), 49-58.

Sigelman, C. K., \& Waitzman, K. A. (1991). The development of distributive justice orientations: Contextual influences on children's resource allocations. Child Development, 62, 1367-1378. 